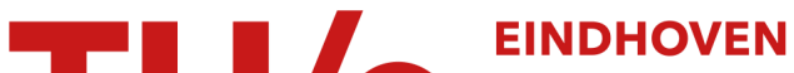 \\ UNIVERSITY OF \\ TECHNOLOGY
}

\section{Impurity effects upon the Verwey transition in magnetite}

Citation for published version (APA):

Brabers, V. A. M., Walz, F., \& Kronmüller, H. (1998). Impurity effects upon the Verwey transition in magnetite. Physical Review B, 58(21), 14163-14166. https://doi.org/10.1103/PhysRevB.58.14163

DOI:

10.1103/PhysRevB.58.14163

Document status and date:

Published: 01/01/1998

\section{Document Version:}

Publisher's PDF, also known as Version of Record (includes final page, issue and volume numbers)

\section{Please check the document version of this publication:}

- A submitted manuscript is the version of the article upon submission and before peer-review. There can be important differences between the submitted version and the official published version of record. People interested in the research are advised to contact the author for the final version of the publication, or visit the $\mathrm{DOI}$ to the publisher's website.

- The final author version and the galley proof are versions of the publication after peer review.

- The final published version features the final layout of the paper including the volume, issue and page numbers.

Link to publication

\section{General rights}

Copyright and moral rights for the publications made accessible in the public portal are retained by the authors and/or other copyright owners and it is a condition of accessing publications that users recognise and abide by the legal requirements associated with these rights.

- Users may download and print one copy of any publication from the public portal for the purpose of private study or research.

- You may not further distribute the material or use it for any profit-making activity or commercial gain

- You may freely distribute the URL identifying the publication in the public portal.

If the publication is distributed under the terms of Article 25fa of the Dutch Copyright Act, indicated by the "Taverne" license above, please follow below link for the End User Agreement:

www.tue.nl/taverne

Take down policy

If you believe that this document breaches copyright please contact us at:

openaccess@tue.nl

providing details and we will investigate your claim. 


\title{
Impurity effects upon the Verwey transition in magnetite
}

\author{
V. A. M. Brabers \\ Department of Physics, Eindhoven University of Technology, P.B. 513, 5600 MB Eindhoven, The Netherlands \\ F. Walz and H. Kronmüller \\ Max-Planck-Institut für Metallforschung, Heisenbergstrasse 1, D-70569, Stuttgart, Germany
}

(Received 22 May 1998)

\begin{abstract}
Magnetite single crystals $\mathrm{Fe}_{3-x} M_{x} \mathrm{O}_{4}$ doped with $M=\mathrm{Ni}, \mathrm{Co}, \mathrm{Mg}, \mathrm{Al}, \mathrm{Ga}$, and $\mathrm{Ti}$ were grown and annealed under a controlled atmosphere to produce homogeneous and oxygen stoichiometric samples. The cation vacancy concentration of the samples was proved to be lower than $10^{-6}$ by means of magnetic disaccommodation spectroscopy. The Verwey temperature shift as function of the substituent concentration was determined from the temperature dependence of the resistivity. The systematics of the transition temperature shift as function of the concentration and nature of the substituents is indicative that the mechanism of the transition is related to the second-neighbor Coulomb interaction of the cations on the octahedral sites.
\end{abstract}

[S0163-1829(98)00846-7]

\section{INTRODUCTION}

Although magnetite $\left(\mathrm{Fe}_{3} \mathrm{O}_{4}\right)$ is one of the most studied magnetic oxides, the investigation of the physical properties of this material is still an intriguing field of research. ${ }^{1}$ At room temperature, the crystal structure of $\mathrm{Fe}_{3} \mathrm{O}_{4}$ is the inverted spinel structure, in which the tetrahedral $A$ sites are occupied by one-third of the $\mathrm{Fe}$ ions as $\mathrm{Fe}^{3+}$ and the remaining $\mathrm{Fe}$ ions are located on the octahedral $B$ sites as mixedvalent $\mathrm{Fe}$ ions with an average charge of $2.5+$. Around 125 $\mathrm{K}$, magnetite undergoes a first-order phase transition, which was already in the 1920's and 1930's probed by anomalies in the magnetization, ${ }^{2}$ specific heat, ${ }^{3}$ and the lattice constant. ${ }^{4}$ Verwey ${ }^{5}$ related this transition to an electronic ordering of $\mathrm{Fe}^{2+}$ and $\mathrm{Fe}^{3+}$ ions on the $B$ sites, causing a decrease in the electrical conductivity of about two orders of magnitude, which is now known as the Verwey transition.

Irrespective of the more and more refined structure models that have been developed to explain the low-temperature charge ordering in magnetite, ${ }^{6-14}$ some basic statements can be made concerning the driving forces of the ordering mechanisms at low temperatures.

(1) The Verwey transition in magnetite is not primarily induced by magnetic interactions, as follows from the small value of the magnetic anisotropy energy accompanying the magnetoelectric effect, ${ }^{15}$ the small change of the saturation magnetization at the transition temperature $T_{v}$ (Ref. 16), and the absence of anomalies of the magnetic anisotropy constants on passing the critical nonstoichiometry parameter $\delta_{t}$ for $\mathrm{Fe}_{3-\delta} \mathrm{O}_{4}$, above which the transition disappears. ${ }^{17}$

(2) The Verwey transition is exceptional in the sense that the ordering mechanism is related to the Coulomb interactions according to which a transition temperature above $10^{4} \mathrm{~K}$ would be expected, whereas the real transition still occurs at low temperatures around $125 \mathrm{~K}$. This apparent contradiction was cleared by Anderson ${ }^{18}$ by taking into account the particular geometry of the spinel lattice. The octahedral sites in the spinel structure are arranged in tetrahedra $B_{4}$, with each site belonging to two adjacent tetrahedra. In this arrangement, short-range order is imposed by the so-called Anderson condition: the charge of the individual tetrahedra must be constant, i.e., two $\mathrm{Fe}^{2+}$ and two $\mathrm{Fe}^{3+}$ ions per tetrahedron. If the interactions leading to the Verwey transition would be restricted to nearest-neighbor pairs, identical energies would be expected for all configurations fulfilling Anderson's condition and no transition should occur. However, there is a transition, which means that the driving mechanism of the transition is achieved by next-nearestneighbor Coulomb interactions.

(3) The discussion as to whether this short-range order persists $^{19,19(\mathrm{~b})}$ above the Verwey transition has been decided positively by recent photoemission spectroscopy experiments on the (100) surface of $\mathrm{Fe}_{3} \mathrm{O}_{4} \cdot{ }^{20,21}$

(4) Since the Verwey ordering mechanism originates from the Coulomb interactions, the effects of substitutions that alter the $\mathrm{Fe}^{2+} / \mathrm{Fe}^{3+}$ ratio on the octahedral sites can give more insight into this phase transition. Miyahara ${ }^{22}$ determined the shift of the transition temperature as a function of the concentration for a number of impurities. Unfortunately, the oxygen stoichiometry affects also the transition temperature. $^{19,23}$ This may explain why no clear relations were found between the transition temperature shifts and the nature or concentration of the substituents. ${ }^{22}$ Aragon et al. ${ }^{23}$ reported two regimes in the nonstoichiometry dependence of the transition temperature on either side of a critical composition $\delta_{c}=0.0117$ for $\mathrm{Fe}_{3-\delta} \mathrm{O}_{4}$, with a first-order transition for $\delta<\delta_{c}$ and a second-order transition for $\delta>\delta_{c}$. Similar results were reported for stoichiometric magnetite single crystals doped with $\mathrm{Zn}$ and $\mathrm{Ti}, \mathrm{Fe}_{3-x} \mathrm{Zn}_{x} \mathrm{O}_{4}$ and $\mathrm{Fe}_{3-x} \mathrm{Ti}_{x} \mathrm{O}_{4}{ }^{24}$

For Al-substituted magnetite a relative weak dependence of the $T_{v}$ shift as a function of the substituent concentration was reported, which was partially attributed to a mixed distribution of $\mathrm{Al}^{3+}$ over the $A$ and $B$ sites. ${ }^{25}$

So far it remains still an open question if there is a general universal dependence of $T_{v}$ upon the dope concentration, irrespective of the nature of the substituent, ${ }^{24}$ which is the 


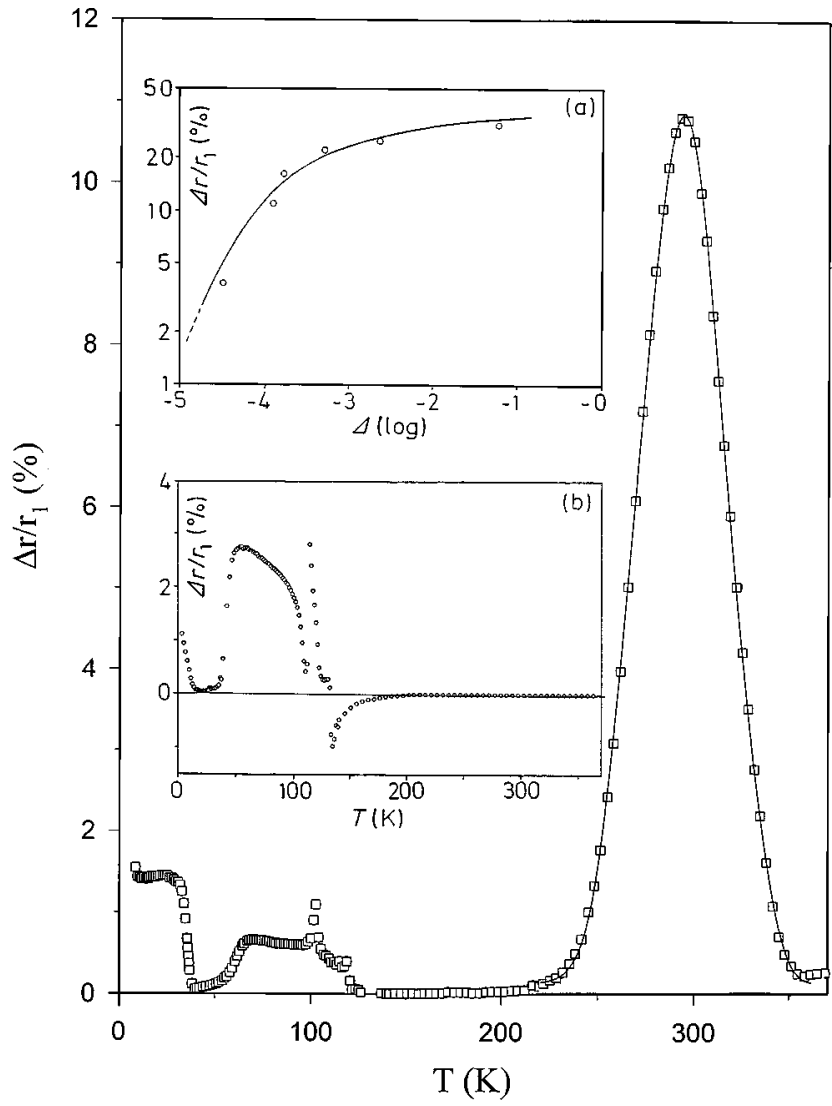

FIG. 1. Disaccommodation spectrum of polycrystalline, vacancy-doped $\mathrm{Fe}_{3-\Delta} \mathrm{O}_{4}\left(\Delta=10^{-4}\right)$, as obtained in the temperature range $4-450 \mathrm{~K}$ ) for the measuring times $t_{1}=1 \mathrm{~s}$ and $t_{2}=180 \mathrm{~s}$. Inset (a) shows the strength of the $300-\mathrm{K}$ relaxation as a function of the vacancy concentration; inset (b) represents the disaccommodation spectrum for oxygen-stoichiometric $\mathrm{Fe}_{2.97} \mathrm{Ni}_{0.03} \mathrm{O}_{4}$.

experimental basis of the mean-field analysis of the Verwey transition. $^{26}$

\section{EXPERIMENT}

To study the effects of impurities on the Verwey transition and to separate the impurity from the oxygen stoichiometry effects, we prepared a number of single crystals $\mathrm{Fe}_{3-x} M_{x} \mathrm{O}_{4}$ with $M=\mathrm{Co}, \mathrm{Ni}, \mathrm{Mg}, \mathrm{Al}, \mathrm{Ga}$, and Ti by means of a floating-zone technique. ${ }^{27}$

After crystallization, the single crystals were additionally heat treated for at least $48 \mathrm{~h}$ at temperatures between 1150 and $1300{ }^{\circ} \mathrm{C}$ in adjusted mixtures of $\mathrm{CO}_{2}$ and $\mathrm{H}_{2}$ to obtain the highest oxygen stoichiometry. With this technique, homogeneous and stoichiometric single crystals with a predetermined impurity composition could be prepared. Because the standard chemical analysis of the oxygen stoichiometry is not accurate enough for our purpose, we used a highsensitivity magnetic disaccommodation technique, allowing us to resolve deviations in the oxygen stoichiometry smaller than $1 \mathrm{ppm}$. The pronounced vacancy-mediated peak near $300 \mathrm{~K}$ in the disaccommodation (DA) spectrum of magnetite ${ }^{28}$ serves as probe for the detection of octahedral vacancies (cf. Fig. 1).

To determine the DA spectra the time dependence of the reciprocal initial susceptibility $r(t, T)=1 / \chi(t, T)$ is measured

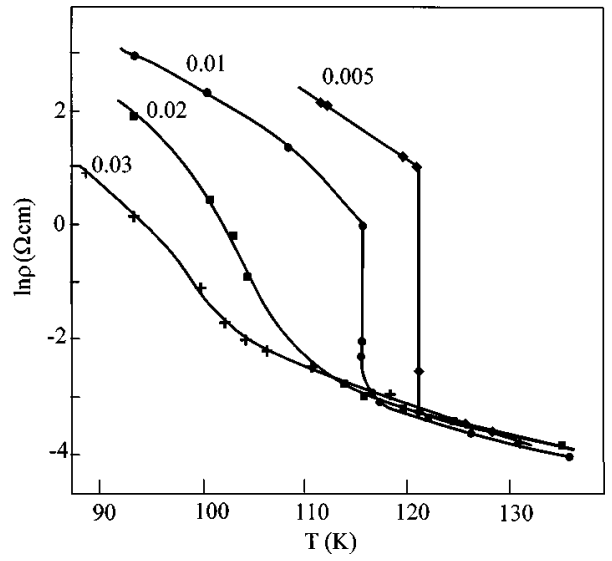

FIG. 2. The resistivity of stoichiometric $\mathrm{Fe}_{3-x} \mathrm{Al}_{x} \mathrm{O}_{4}$ single crystals with $x=0.005,0.01,0.02$, and 0.03 as function of temperature.

at each temperature using an automated LC oscillator technique. ${ }^{29}$ The DA spectra are presented by the isochronal curves, displaying the relative reluctivity at different time intervals $\left(t_{1}, t_{2}\right):{ }^{30}$

$$
\frac{\Delta r}{r_{1}}=\frac{r\left(t_{2}, T\right)-r\left(t_{1}, T\right)}{r\left(t_{1}, T\right)} .
$$

As an example, we show in Fig. 1 the vacancy-induced $300-\mathrm{K}$ relaxation of polycrystalline $\mathrm{Fe}_{3-\delta} \mathrm{O}_{4}$, with $\delta=10^{-4}$ together with its strength dependence on the inherent vacancy content, cf. inset (a). In all our substituted samples the relaxations due to electronic processes are distinctly present in the temperature range below $150 \mathrm{~K}$, whereas the vacancy induced $300-\mathrm{K}$ peak is completely absent, thus indicating a vacancy concentration of lower than $10^{-6}$; cf. inset (b) of Fig. 1 representing as a typical example the disaccommodation spectra of $\mathrm{Fe}_{2.97} \mathrm{Ni}_{0.03} \mathrm{O}_{4}$.

The Verwey temperature of the samples was determined from the temperature dependence of the electrical conductivity being measured by a four-probe technique.

\section{RESULTS AND DISCUSSION}

In Fig. 2 the electrical resistivity of the Al-doped magnetite samples is logarithmically plotted as function of the temperature. In contrast to Ref. 25 , we found a strong dependence of the transition temperature upon the concentration $x$. For $x=0.005$ and $x=0.01$ a sharp first-order transition was observed, whereas for $x=0.02$ and 0.03 a gradual change was observed pointing to a second-order transition. The maximum in the derivative of the $\ln \rho-T$ plot of these compositions was taken as the transition temperature. From the data of Fig. 2 it follows that the critical Al concentration for the transition from first to second order lies between 0.01 and 0.02 , comparable with the value of 0.012 for the $\mathrm{Zn}$ or $\mathrm{Ti}$ substitutions. ${ }^{24}$ The weaker composition dependence of $T_{v}$ for $\mathrm{Fe}_{3-x} \mathrm{Al}_{x} \mathrm{O}_{4}$ as reported by Kozłowski et al. may be explained by their different preparation technique that resulted in less perfect $\mathrm{Al}$ homogeneity. ${ }^{25}$

Figure 3 presents the resistivity measurements of $\mathrm{Fe}_{3-x} \mathrm{Ga}_{x} \mathrm{O}_{4}$ with $x=0.05$ and 0.1 and stoichiometric $\mathrm{Fe}_{3} \mathrm{O}_{4}$. The substituent concentration is much higher than that of the Al system; the transition seems to be of first order and the 


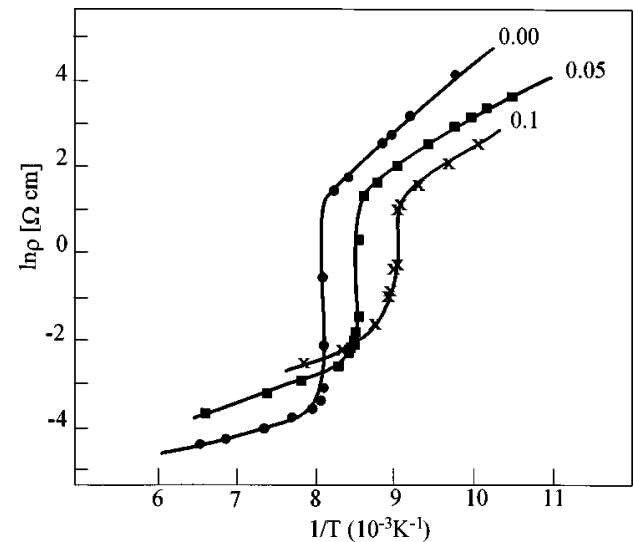

FIG. 3. The resistivity of stoichiometric single crystals $\mathrm{Fe}_{3-x} \mathrm{Ga}_{x} \mathrm{O}_{4}$ with $x=0,0.05$, and 0.10 as a function of the reciprocal temperature.

transition temperatures of 116.9 and $110.6 \mathrm{~K}$ for $x=0.05$ and $x=0.10$, respectively, are shifted in a less pronounced way. For pure magnetite, a transition temperature of $123.9 \mathrm{~K}$ is found.

Doping magnetite with $\mathrm{Ni}, \mathrm{Co}$, or $\mathrm{Mg}$ yields a transition temperature shift that is in between that of $\mathrm{Ga}$ and $\mathrm{Al}$ as can be seen from the $\Delta T_{v}$ plot versus concentration in Fig. 4. For all the measured concentrations, sharp transitions were observed, thus suggesting that for all these samples the transition is still of first order. Additionally, some data for Ti substitution in stoichiometric magnetite are plotted in Fig. $4{ }^{26,31}$ Despite some qualitative agreement with the data reported by Miyahara, ${ }^{22}$ in particular concerning the weak influence of the Ga substitution, there remain substantial differences with our numerical data that are supposed to have their origin in the nonstoichiometry of Miyahara's specimens.

The $T_{v}$ shift versus the substituent concentration reveals specific effects of the various substituents, which were up until now not so evident. $\mathrm{Ni}, \mathrm{Co}$, and $\mathrm{Mg}$ are all bivalent ionic substituents in magnetite. All three metals give similar shifts for $T_{v}$, slightly increasing from $12 \mathrm{~K}$ for Ni to $16 \mathrm{~K}$ for $\mathrm{Mg}$, if the impurity content is equal to $x=0.03$. This small increase can be understood if we take into consideration that $\mathrm{Co}$ and $\mathrm{Mg}$ are slightly inverted, as in $\mathrm{MgFe}_{2} \mathrm{O}_{4}$

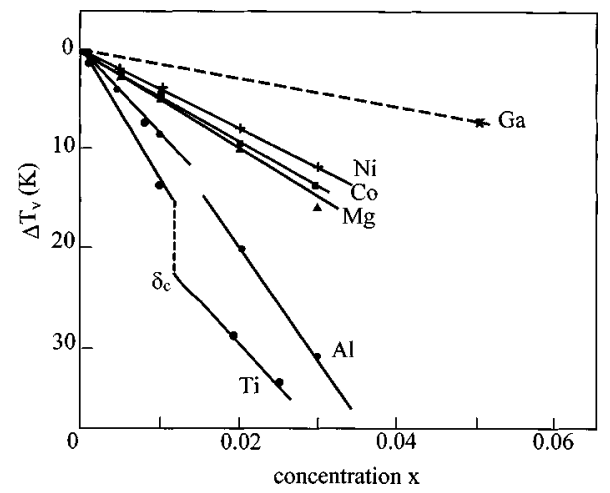

FIG. 4. The shift of the Verwey transition temperature for substituted stoichiometric magnetites $\mathrm{Fe}_{3-x} \mathrm{M}_{x} \mathrm{O}_{4}$, with $M=\mathrm{Ga}, \mathrm{Ni}$, $\mathrm{Co}, \mathrm{Mg}, \mathrm{Al}$, and $\mathrm{Ti}$. The $\mathrm{Ti}$ data are from Refs. 26 and $31(x$ $=0.003$ and 0.008 ). and $\mathrm{CoFe}_{2} \mathrm{O}_{4},{ }^{32}$ i.e., $5-20 \%$ of the $\mathrm{Mg}$ or Co ions are located on $A$ sites, whereas Ni will remain at the $B$ sites. Since these cations are two valent, the ratio of $B$-sited bi- and trivalent cations is for $\mathrm{Ni}$ exactly 2 , which is a stipulation for perfect Verwey ordering, whereas for $\mathrm{Co}$ and $\mathrm{Mg}$ this ratio deviates weakly from 2 .

Honig and co-workers ${ }^{24,26}$ reported the concentration dependence of the $T_{v}$ shift in $\mathrm{Zn}$-substituted magnetite to be about two times larger, as we observed for the $\mathrm{Ni}^{2+}$ magnetites. $\mathrm{Zn}^{2+}$ is known to occupy $A$ sites, thereby changing the $\mathrm{Fe}^{2+} / \mathrm{Fe}^{3+}$ ratio on the $B$ sites which, evidently, proves to be more effective in disturbing the Verwey order than the replacement of an equal number of octahedral $\mathrm{Fe}^{2+}$ ions by other two-valent ions $\mathrm{M}^{2+}$. This becomes plausible by considering that such $B$-site-substituted $\mathrm{M}^{2+}$ ions-within a low-enough concentration range where they cannot hurt the Anderson criterion-in contrast to $\mathrm{Fe}^{2+}$ sites are immobile and thereby may even contribute to a stabilization of the ordered phase. The order-disturbing effect of $\mathrm{Zn}^{2+}$ substitutions, on the other hand, results from the fact that an equal amount of octahedral $\mathrm{Fe}^{2+}$ has to be replaced by $\mathrm{Fe}^{3+}$, which means that $x B_{4}$ units have a charge of $11^{+}$instead of $10^{+}$, thereby destroying the equivalency of the $B_{4}$ units. This elucidates why $\mathrm{Zn}$, though not entering the $B$ lattice, has a larger effect upon $T_{v}$ than the two-valent substitutions on the octahedral lattice. Furthermore, it is an interesting observation that trivalent $\mathrm{Ga}^{3+}$, which, at least for low concentrations, enters preferentially on the tetrahedral sites, ${ }^{33,34}$ reveals a lower composition dependence of $\Delta T_{v}$. If we estimate that only $\frac{1}{3}$ of the Ga ions enter the octahedral sites, ${ }^{34}$ the $T_{v}$ shift corresponding to the octahedral $\mathrm{Ga}^{3+}$ concentration would be identical to that of the $\mathrm{Ni}^{2+}$ concentration, thus indicating comparable charge-order perturbations for both fixed $\mathrm{M}^{3+}$ and $M^{2+}$ ions on $B$ sites. However, the $\mathrm{Al}^{3+}$ substitutions show a much stronger effect, which does not fit into the picture discussed above. This incompatibility may be explained in terms of the ionic radii of $\mathrm{Al}^{3+}(0.535 \AA)$ and $\mathrm{Ga}^{3+}(0.620 \AA)$ of which the latter one is much closer to that of the octahedral $\mathrm{Fe}^{3+}(0.645 \AA)$. The geometry of a $B_{4}$ unit containing one small $\mathrm{Al}^{3+}$ ion will be more deformed, resulting in a variation of the Coulomb energy and, consequently, a larger effect upon the Verwey ordering. In contrast to $\mathrm{Al}^{3+}$, the ionic radii of the bivalent ions $\mathrm{Ni}^{2+}, \mathrm{Co}^{2+}, \mathrm{Mg}^{3+}$ $(0.69,0.745,0.720 \AA)$ - though being smaller than that of $\mathrm{Fe}^{2+}(0.78 \AA)$-range in between the radii of $\mathrm{Fe}^{3+}$ and $\mathrm{Fe}^{2+}$ and thus, evidently, are disturbing to a smaller extent the ionic packing that governs the Verwey transition. ${ }^{35}$

Recently, it has also been suggested that magnetic interactions could explain a universal $T_{v}$ shift versus the concentration of respective substituents, this shift being proportional to the population difference, $\Delta \mathrm{Fe}^{3+}$ of the $\mathrm{Fe}^{3+}$ cations on the tetrahedral and octahedral sublattices. ${ }^{25}$ However, the results obtained on the bivalent substitutions, for which $\Delta \mathrm{Fe}^{3+}=0$, do not support this suggestion. Moreover, $\mathrm{Al}^{3+}$ substitutes for low concentrations only on $B$ sites, ${ }^{34}$ which would imply $\Delta \mathrm{Fe}^{3+}=x$, thereby inducing-in terms of the proposed scaling-a much smaller $T_{v}$ shift than observed. Further, if magnetic interactions were involved in the mechanism of the Verwey ordering, one would expect a substantial difference between the doping with magnetic $\left(\mathrm{Ni}^{2+}\right.$, 
$\left.\mathrm{Co}^{2+}\right)$ and nonmagnetic $\left(\mathrm{Mg}^{2+}\right)$ ions, which is not observed. Since the magnetic interactions in magnetite, leading to the magnetically ordered state, are nearest-neighbor interactions, where the octahedral nearest-neighbor configurations are controlled by the Anderson criterion, it is unlikely that magnetic interactions play a dominant role in the Verwey order- ing mechanism. In contrast, the systematics in the $T_{v}$ shifts, in dependence of varying concentrations of specific substituents as we have found, are in favor of the next-nearestneighbor Coulomb interactions as driving forces for the Verwey ordering.
${ }^{1}$ For a recent review, see V. A. M. Brabers, in Handbook of Magnetic Materials, edited by K. H. J. Buschow (Elsevier Science, Amsterdam, 1995), Vol. 8, Chap. 3.

${ }^{2}$ P. Weiss and R. Forrer, Ann. Phys. (Paris) 12, 330 (1929).

${ }^{3}$ G. S. Parks and K. K. Kelley, J. Phys. Chem. 30, 47 (1926).

${ }^{4}$ B. S. Ellefson and N. W. Taylor, J. Chem. Phys. 2, 58 (1934).

${ }^{5}$ E. W. J. Verwey, Nature (London) 144, 327 (1939); E. W. J. Verwey and P. W. Haayman, Physica (Utrecht) 8, 979 (1941).

${ }^{6}$ E. W. J. Verwey, P. W. Haayman, and F. C. Romeyn, J. Chem. Phys. 15, 181 (1947)

${ }^{7}$ G. Shirane, S. Chikazumi, J. Akimisu, K. Chiba, M. Matsui, and Y. Fujii, J. Phys. Soc. Jpn. 39, 949 (1975).

${ }^{8}$ Y. Yoshida and S. Iida, J. Phys. Soc. Jpn. 42, 230 (1977).

${ }^{9}$ M. Iizumi, T. F. Koetzele, G. Shirane, S. Chikazumi, M. Matsui, and S. Todo, Acta Crystallogr., Sect. B: Struct. Crystallogr. Cryst. Chem. 38, 2121 (1982).

${ }^{10}$ J. M. Zuo, J. C. H. Spence, and W. Petuskey, Phys. Rev. B 42, 8451 (1990).

${ }^{11}$ M. Mizoguchi, J. Phys. Soc. Jpn. 44, 1501 (1978).

${ }^{12}$ M. Mizoguchi, J. Phys. Soc. Jpn. 54, 2168 (1985); 54, 4295 (1985).

${ }^{13}$ S. Iida, Philos. Mag. B 42, 349 (1980).

${ }^{14}$ K. Siratori, E. Kita, G. Kaji, A. Tasaki, S. Kimura, I. Shindo, and K. Kohn, J. Phys. Soc. Jpn. 47, 1779 (1979); G. T. Rado and J. M. Ferrari, Phys. Rev. B 12, 5166 (1975); Y. Miyamoto and M. Shindo, J. Phys. Soc. Jpn. 62, 1423 (1993).

${ }^{15}$ E. Kita, K. Siratori, K. Kohn, A. Tasaki, S. Kimura, and I. Shindo, J. Phys. Soc. Jpn. 47, 1788 (1979).

${ }^{16}$ S. Umemura and S. Iida, J. Phys. Soc. Jpn. 40, 679 (1976); M. Matsui, S. Todo, and S. Chikazumi, ibid. 42, 47 (1977).

${ }^{17}$ Z. Kakol and J. M. Honig, Phys. Rev. B 40, 9090 (1989).

${ }^{18}$ P. W. Anderson, Phys. Rev. 102, 1008 (1956).

${ }^{19}$ (a) E. Gmelin, N. Lenge, and H. Kronmueller, Phys. Status Solidi
A 79, 465 (1983); (b) J. P. Shepherd, J. W. Koenitzer, R. Aragon, and J. M. Honig, Phys. Rev. B 43, 8461 (1991); (c) M. O. Rigo, J. F. Mareche, and V. A. M. Brabers, Philos. Mag. B 48, 421 (1983).

${ }^{20}$ J. H. Park, L. H. Tjeng, J. W. Allen, P. Metcalf, and C. T. Chen, Phys. Rev. B 55, 12813 (1997).

${ }^{21}$ A. Chainani, T. Yokoya, T. Morimoto, and T. Takahashi, Phys. Rev. B 51, 17976 (1995).

${ }^{22}$ Y. Miyahara, J. Phys. Soc. Jpn. 32, 629 (1972).

${ }^{23}$ R. Aragon, D. Buttrey, J. P. Shepherd, and J. M. Honig, Phys. Rev. B 31, 430 (1985); R. Aragon and J. M. Honig, ibid. 37, 209 (1988).

${ }^{24}$ A. Kozlowski, Z. Kakol, D. Kim, R. Zalecki, and J. M. Honig, Phys. Rev. B 54, 12093 (1996).

${ }^{25}$ A. Kozlowski, P. Metcalf, Z. Kakol, and J. M. Honig, Phys. Rev. B 53, 15113 (1996).

${ }^{26}$ J. M. Honig, J. Alloys Compd. 229, 24 (1995).

${ }^{27}$ V. A. M. Brabers, J. Cryst. Growth 8, 26 (1971).

${ }^{28}$ F. Walz, V. A. M. Brabers, S. Chikazumi, H. Kronmüller, and M. O. Rigo, Phys. Status Solidi B 110, 471 (1982).

${ }^{29}$ F. Walz, Phys. Status Solidi A 82, 179 (1984).

${ }^{30} \mathrm{H}$. Kronmüller, Nachwirkung in Ferromagnetika (SpringerVerlag, Berlin, 1968).

${ }^{31}$ A. J. M. Kuipers and V. A. M. Brabers, Phys. Rev. B 20, 594 (1979); J. Phys. (Paris), Colloq. 38, C1-233 (1977).

${ }^{32}$ V. A. M. Brabers and J. Klerk, J. Phys. (Paris), Colloq. 38, C1207 (1977); Y. Kawai, V. A. M. Brabers, and Z. Šimša, IEEE Trans. Magn. 30, 966 (1994).

${ }^{33}$ A. Ole, Acta Phys. Pol. 30, 125 (1966); H. Gamari-Seale and P. Papamantellos, Phys. Status Solidi 29, 323 (1968).

${ }^{34}$ M. Rosenberg, P. Deppe, H. U. Janssen, V. A. M. Brabers, F. S. Li, and S. Dey, J. Appl. Phys. 57, 3740 (1985).

${ }^{35}$ R. D. Shannon, Acta Crystallogr., Sect. A: Cryst. Phys., Diffr., Theor. Gen. Crystallogr. 32, 751 (1976). 